\title{
Da institucionalização do Sistema de Pós- graduação ao Plano Nacional de Pós-Graduação (2011-2020): desafios e perspectivas
}

\section{The institutionalization of the Graduate System to the National} Graduate Plan (2011-2020): challenges and perspectives

De la institucionalización del Sistema de Posgrado al Plan Nacional de Posgrado (2011-2020): desafios y perspectivas

ALEXANDRE SHIGUNOV NeTODa

MÁRCIO GIUSTI TREVISOL (iDb

MARIA de LouRdes PINTO de ALMEIDA (Dc

\section{Resumo}

O artigo é resultado da pesquisa sobre pós-graduação no Brasil a partir de sua institucionalização até o Plano Nacional de Pós-Graduação (2011-2020). O objetivo é historicizar os planos de pós-graduação, sobretudo, as questões formuladas no PNPG (2011-2020) e suas recomendações subsequentes nos relatórios 2016, 2018 e 2020. As metas e objetivos propostos nos PNPG ditam o ritmo e definem os caminhos que a nação pretende para o futuro, relacionados as pesquisas que serão desenvolvidas na pós-graduação. Ressalta-se, neste contexto, áreas são

\footnotetext{
a Instituto Federal de Educação, Ciência e Tecnologia, Itapetininga, SP, Brasil. Doutor em Educação, e-mail: shigunov.ifsp.edu@gmail.com

b Universidade do Oeste de Santa Catarina (Unoesc), Joaçaba, SC, Brasil. Doutor em Educação, e-mail: marcio.trevisol@unoesc.edu.br

' Universidade do Oeste de Santa Catarina (Unoesc), Joaçaba, SC, Brasil; Universidade Estadual de Campinas (Unicamp), Campinas, SP, Brasil. Doutor em Educação, e-mail: malu04@gmail.com
} 
acentuadas como prioritárias, fontes de financiamento são definidas e formas de avaliação são implementadas. A reflexão sobre os PNPGs permite, além do entendimento da conjuntura política, capacitar e organizar os programas de pósgraduação para que tenham impacto na pesquisa sem perder sua identidade e compromisso com a região que estão localizados. Trata-se de uma pesquisa exploratória de cunho analítico e com coleta de dados documental. A metodologia utilizada para investigação foi a histórico-crítica. De acordo com a pesquisa, podese afirmar que os PNPG estão interligados com o contexto que foram gestados e revelam o projeto de nação preterido pelo (des)governo, além, de estipular como meta a consolidação da pesquisa nos mesmos níveis de competividade global, com ênfase em investigações de alto impacto para o mercado capitalista.

Palavras-chave: Institucionalização. Sistema de Pós-Graduação. PNPG. Pós-graduação.

\section{Abstract}

The article is the result of research on postgraduate studies in Brazil from its institutionalization to the National Postgraduate Degree Plan (2011-2020). The objective is to historicize the postgraduate plans, above all, the questions formulated in the PNPG (2011-2020) and their subsequent recommendations in the 2016, 2018 and 2020 reports. The goals and objectives proposed in the PNPG dictate the pace and define the paths that the nation intends for the future, related to the research that will be developed in postgraduate studies. In this context, it is emphasized that areas are emphasized as priorities, sources of financing are defined and forms of evaluation are implemented. The reflection on the PNPGs allows, in addition to understanding the political situation, to train and organize postgraduate programs so that they have an impact on research without losing their identity and commitment to the region they are located in. It is an exploratory research of an analytical nature and with documentary data collection. The methodology used for investigation was historical-critical. According to the research, it can be said that the PNPGs are interconnected with the context that were generated and reveal the nation project neglected by (not) government overnment, in addition to stipulating as a goal the consolidation of research at the same levels of global competitiveness, with an emphasis on high-impact investigations for the capitalist market.

Keywords: Institutionalization. Postgraduate System. PNPG. Postgraduate studies.

\section{Resumen}

El artículo es el resultado de una investigación sobre estudios de posgrado en Brasil desde su institucionalización hasta el Plan Nacional de Posgrado (2011-2020). El objetivo es historizar los planes de egreso, sobre todo, las preguntas formuladas en el PNPG (2011-2020) y sus posteriores recomendaciones en los informes 2016, 2018 y 2020. Las metas y objetivos propuestos en el PNPG marcan el ritmo y definen el 
caminos que la nación propone para el futuro, relacionados con la investigación que se desarrollará en los estudios de posgrado. En este contexto, se enfatiza que se enfatizan áreas como prioritarias, se definen fuentes de financiamiento y se implementan formas de evaluación. La reflexión sobre los PNPGs permite, además de comprender la situación política, capacitar y organizar programas de posgrado para que incidan en la investigación sin perder su identidad y compromiso con la región en la que se ubican. Se trata de una investigación exploratoria de carácter analítico y con recogida de datos documentales. La metodología utilizada para la investigación fue histórico-crítica. De acuerdo con la investigación, se puede decir que los PNPG están interconectados con el contexto que se generaron y revelan el proyecto de nación desatendido por el (des) gobierno, además de estipular como meta la consolidación de la investigación en los mismos niveles de competitividad global, con énfasis en investigaciones de alto impacto para el mercado capitalista.

Palabras clave: Institucionalización. Sistema de Postgrado. PNPG. Estudios de posgrado.

\title{
Introdução
}

\begin{abstract}
A partir da concepção de que o mundo da produção se encontra ingressado na quarta revolução, o campo de poder (o Estado) e as agências de fomento à pesquisa e à pós-graduação publicam editais que priorizam as chamadas ciências naturais, criadoras de tecnologias, invenções e inovações materiais, em desapreço às humanidades, com o propósito de obter vantagens competitivas no mundo da produção de mercadorias (AZEVEDO; OLIVEIRA; CATANI, 2016, p. 786).
\end{abstract}

A epígrafe apresenta de maneira sucinta a importância de se discutir a pósgraduação no Brasil. Além de formação de mestres e doutores no Brasil, o Sistema de Pós-Graduação (SNPG), integrado por programas de pós-graduação, avaliados e reconhecidos pela Coordenação de Pessoal de Nível Superior (CAPES), tem sido responsável, em grande medida, pela produção do conhecimento científico (OLIVEIRA, 2015). O nascimento da CAPES foi um marco para o desenvolvimento da Pós-Graduação. Para Coury (2014, p. 38), “embora a CAPES tenha nascido como uma campanha voltada para o aperfeiçoamento dos docentes universitários, logo sua atuação seria ampliada para atender às demandas de qualificação de diferentes seguimentos da sociedade. Conforme Bianchetti (2009, p. 38).

[...] formalmente, a CAPES foi criada no ano de 1951, no bojo de uma política de governo por meio da qual, juntamente com os órgãos de avaliação, acompanhamento e financiamento, se buscava, via criação de cursos de pós- 
graduação, estímulo à organização e ao desenvolvimento de projetos, indução a pesquisa, contribuições para melhorar a posição do país no cenário mundial.

Neste sentido, a CAPES foi fundamental para a institucionalização do Sistema Nacional de Pós-Graduação e, atualmente, é necessária para a qualificação dos programas de pesquisa de pós-graduação. Neste panorama, o Sistema Nacional de pós-graduação alinhado as prerrogativas e delineamentos propostos pela CAPES tem se tornado um dos principais vetores de pesquisa e de desenvolvimento para o país nas mais diversas áreas.

O objetivo deste texto foi historiar e refletir sobre o percurso, as metas e os objetivos da pesquisa no Brasil perpassando a institucionalização da pós-graduação e os PNPGs, sobretudo, o PNPG (2011-2020) com os seus relatórios. Ao realizar uma investigação dessa envergadura é possível conferir uma relação entre os objetivos propostos nos documentos com o delineamento político da proposta de nação elaborado pelo governo (ou desgoverno atual) em seus diferentes contextos históricos.

O artigo foi organizado em 03 secções: i) a institucionalização do Sistema de Pós-Graduação - PNPG onde é apresentado os principais documentos e leis que institucionalizaram a pós-graduação no país; ii) é apresentada a historicidade dos PNPG, as metas e objetivos articulados com a concepção de nação e desenvolvimento para o país em cada momento contexto; iii) são discutidas e apresentadas as metas e objetivos contidos no PNPG (2011-2020) e seus relatórios, sobretudo de 2016, 2018 e 2019.

Partido da análise dos dados coletados no discurso dos documentos oficiais é possível apontar que a pós-graduação no Brasil elege áreas prioritárias que, segundo os Planos Nacionais de Pesquisa garantem o desenvolvimento de pesquisas de alto impacto (para o mercado de trabalho) e necessárias para colocar o país nos mesmos índices de pesquisa mundiais. Assim sendo, com relação ao percurso, metas e objetivos a pós-graduação deverá ser organizada pela lógica da competividade global, pelos critérios definidos pelos organismos internacionais (UNESCO, OCDE e Banco Mundial). A estruturação da pós-graduação nestes moldes coloca em séria crise os Programas de Pós-graduação Stricto Sensu, vinculados a áreas das humanidades. 


\section{A institucionalização do Sistema Nacional de Pós- Graduação - PNPG}

Embora a pós-graduação esteja presente na vida educacional brasileira a partir da década de 1930 é comum presumir que a pós-graduação brasileira surgiu na década de 1960 com a Reforma Universitária. Ainda assim, somente com a LDB/61 (Lei de Diretrizes e Bases) é que formalmente a pós-graduação é considerada oficialmente como nível de ensino. Acontecimento importante e que contribuiu para a expansão da pós-graduação foi a aprovação do Estatuto do Magistério Superior que vinculou a titulação ao ingresso e ascensão na carreira docente. Interessa destacar que esse processo de expansão e desenvolvimento da pós-graduação nacional, via legislação específica, estava alinhado à concepção do Governo militar que acreditava que a pós-graduação poderia contribuir para o desenvolvimento nacional e aos interesses político-econômicos (MEGID NETO, 1999).

O processo de institucionalização do Sistema Nacional de Pós-Graduação brasileiro foi formalmente concebido na década de 1960 e pode ser classificada em três fases específicas. A primeira fase denominada de implantação e expansão do Sistema Nacional de Pós-Graduação tem início na década de 1960 e prolonga-se até o final da década de 1970. A segunda fase alcunhada de consolidação da pós-graduação ocorre durante a década de 1980, momento histórico em que transcorre a consolidação dos cursos de pós-graduação, retração da expansão dos cursos e racionalização de recursos. A terceira fase designada de avaliação institucional dos programas é caracterizada pela busca de novos modelos ou estrutura de cursos de pós-graduação e pela moderada expansão de cursos e vagas (MEGID NETO, 1999).

A criação do Conselho Nacional de Pós-Graduação estabelecia que no planejamento da pós-graduação deviam ser considerados os levantamentos e estimativas das universidades, além das necessidades nacionais e regionais para próximo triênio, principalmente no tocante aos docentes de ensino superior, inclusive nas instituições particulares, pesquisadores nos diferentes ramos do saber, profissionais altamente especializados, de acordo com os planos coordenados pelo órgão setorial respectivo (MEGID NETO, 1999). 
Cumprindo com suas atribuições o Conselho Nacional de Pós-Graduação elaborou e propôs o I Plano Nacional de Pós-Graduação. Entretanto, e apesar de sua importância para a institucionalização e consolidação da pós-graduação nacional o Conselho Nacional de Pós-Graduação não teve longevidade, foi extinto em 28 de dezembro de 1981.

\section{Historicidade dos PNPG: metas e objetivos}

Com o objetivo de institucionalizar e consolidar o sistema nacional de pósgraduação no Brasil foram implementados 5 (cinco) planos com o objetivo de direcionar a política nacional de pós-graduação nacional. Os planos que tiveram início em meados da década de 1970, mas que apesar de serem contínuos tiveram períodos de exiguidade. A figura 1 (um) exemplifica a historicidade dos Planos Nacionais de Pós-Graduação.

Figura 2 - Os Planos Nacionais de Pós-Graduação

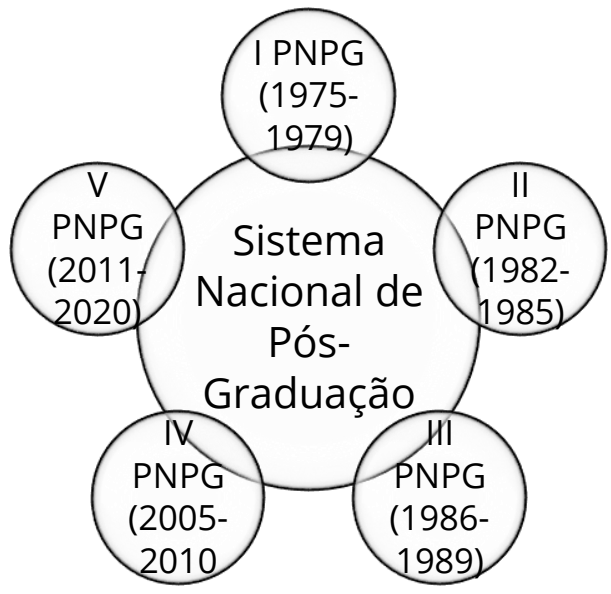

Fonte: Autores (2020)

De acordo com Megid Neto (1999) o Conselho Nacional de Pós-Graduação considera que o sistema nacional de pós-graduação precisa se consolidar sob o prisma institucional e financeiro, de modo a permitir que o sistema universitário brasileiro alcance um novo patamar, em que as atividades de pós-graduação desempenharão uma importância estratégia crescente. $\mathrm{O}$ documento elaborado está embasado no Parecer Newton Sucupira ao considerar os níveis de ensino da pós-graduação. 
O I PNPG foi dividido em 4 (quatro) partes, uma introdução, a análise da evolução da pós-graduação no Brasil, os objetivos e diretrizes gerais do PNPG e os programas e metas de expansão. Ao realizar a análise da evolução da pós-graduação no Brasil o documento expõe as principais características das atividades, analisa o processo de surgimento dos cursos e instituições e diagnostifica os principais problemas atuais da pós-graduação, destacando os problemas de estabilização, desempenho e de crescimento.

O I PNPG se harmoniza com as orientações do III Plano Nacional de Desenvolvimento (PND) e com as indicações do III Plano Básico de Desenvolvimento Científico e Tecnológico (PBDCT). Decomposto em cinco partes o plano retrata as premissas básicas da política nacional de pós-graduação, a situação da pós-graduação, o papel da pós-graduação no contexto nacional, os objetivos básicos do plano nacional de pós-graduação e por fim as prioridades e diretrizes.

Consideram que a Política Nacional de Pós-Graduação, Megid Neto, 1999, apontam que está embasada nas seguintes premissas: a existência de um número crescente de profissionais, pesquisadores e docentes altamente qualificados viabiliza um desenvolvimento científico, tecnológico e cultural próprio e representa garantia real para a afirmação dos valores genuinamente brasileiros. A consolidação da pósgraduação depende de um sistema universitário e de institutos de pesquisa estável e dinâmico em todos os seus níveis e setores. O seu desenvolvimento pressupõe a existência de condições materiais e institucionais indispensáveis para a plena realização de suas finalidades. Neste sentido, a pós-graduação baseia-se na existência de docentes e pesquisadores efetivamente engajados na produção de novos conhecimentos científicos, tecnológicos ou culturais em instituições que lhes garantam adequada dedicação, carga horária de ensino compatível com a pesquisa e as outras formas de produção intelectual (BRASIL, 1975).

Ao analisar a evolução da pós-graduação o documento descreve as características das atividades ligadas à pós-graduação, analisa o processo de surgimento dos cursos e instituições e apresenta um diagnóstico dos principais problemas enfrentados por esse nível de ensino no Brasil. O entendimento é que a pós-graduação nacional, de acordo com Megid Neto, (1999), propiciou uma 
indiscutível contribuição para a melhoria da qualificação docente para o atendimento das necessidades do mercado, entretanto, por uma falta critérios específicos e de orientação do Ministério da Educação e Cultura surgiram 3 problemas principais: problema de estabilização, de desempenho e de crescimento.

As diretrizes que devem permear as atividades e ações do I PNPG são: institucionalizar o sistema, consolidando-o como atividade regular no âmbito das universidades e garantindo-lhe um financiamento estável; elevar os seus atuais padrões de desempenho e racionalizar a utilização dos recursos; planejar sua expansão em direção a uma estrutura mais equilibrada entre as áreas de trabalho educacional e científico e entre as regiões do país (BRASIL, 1975).

Pela primeira vez se define a estrutura do sistema nacional de pós-graduação, que será composto dos seguintes órgãos: do Conselho Nacional de Pós-Graduação, como órgão colegiado interministerial, com funções de formular a política geral de pós-graduação e coordenar a sua execução; do Conselho Federal de Educação com funções de normalizar os procedimentos jurídicos gerais e credenciar os cursos; do Departamento de Assuntos Universitários - DAU com função de executar as políticas e programas; do Conselho Nacional de Desenvolvimento Científico e Tecnológico - CNPq com funções de assessorar a formulação da política de desenvolvimento científico e tecnológico, coordenar e apoiar as atividades de produção científica; de outros órgãos e agências, governamentais ou não, com funções de apoio e estímulo às atividades de pesquisa e formação de recursos humanos; das instituições de ensino superior e dos centros de pesquisa, públicos e privados, onde houver cursos de pós-graduação, com atribuições diretamente relacionadas ao funcionamento dos cursos (BRASIL, 1975).

No item programas e metas de expansão o I PNPG aponta a expansão projetada para o período 1975-1979, metas em relação a quantidade de docentes titulados e da ampliação da capacidade de titulação, sendo a preocupação primordial fixar valores e quantitativo viável de serem atingidos no período. Para tal propõe três programas que permitirão o alcance das metas: a concessão de bolsas de estudos, a capacitação institucional do corpo docente e a admissão de professores (BRASIL, 1975). 
Cabe destacar que enquanto o I PNPG tinha como objetivo a expansão e consolidação do sistema nacional de pós-graduação brasileiro, o II PNPG visava prioritariamente a questão da qualidade da oferta da pós-graduação e da formação de recursos humanos. (BARROS, 1998; MEGID NETO, 1999; ALVES E OLIVEIRA, 2015; MARTINS, 2018).

O documento do V PNPG (2011-2020) ao analisar o primeiro PNPG (19751979) constatou que ele se originou da confirmação de que o processo de expansão da pós-graduação era considerado parcialmente espontâneo, desordenado e compelido por motivos conjunturais. $\mathrm{E}$ que desde aquele dado momento a expansão da pós-graduação deveria se transformar em objeto de planejamento e política pública, sendo a pós-graduação considera um subsistema do sistema universitário e do sistema educacional (BRASIL, 2010).

O II PNPG é marcado pela retração da expansão dos cursos e das vagas em função da crise econômica do final dos anos 1970, momento em que ocorre as primeiras iniciativas de avaliação da qualidade do sistema (MEGID NETO, 1999).O II Plano Nacional de Pós-Graduação aprovado por meio Decreto $n^{\circ}$ 87.814, de 16/11/82 e publicado no DOU de 18/11/82, com validade para o quadriênio 19821985 fixou os objetivos, as prioridades e as diretrizes que consubstanciam a política do Ministério da Educação e Cultura para a área de pós-graduação. Tanto na estrutura quanto no conteúdo, o II PNPG se harmoniza com as orientações do III Plano Nacional de Desenvolvimento (PND) e com as indicações do III Plano Básico de Desenvolvimento Científico e Tecnológico (PBDCT). Decomposto em cinco partes o plano retrata as premissas básicas da política nacional de pósgraduação, a situação da pós-graduação, o papel da pós-graduação no contexto nacional, os objetivos básicos do plano nacional de pós-graduação e por fim as prioridades e diretrizes.

Neste período, a Política Nacional de Pós-Graduação está embasada nas seguintes premissas: a existência de um número crescente de profissionais, pesquisadores e docentes altamente qualificados; a consolidação da pós-graduação depende de um sistema universitário e de institutos de pesquisa estável e dinâmico em todos os seus níveis e setores; sistema de pós-graduação baseia-se na existência 
de docentes e pesquisadores efetivamente engajados na produção de novos conhecimentos científicos, tecnológicos ou culturais em instituições que lhes garantam adequada dedicação horária, carga de ensino compatível com a pesquisa e as outras formas de produção intelectual (BRASIL, 1982).

Em relação a situação da pós-graduação brasileira o documento salienta que apesar dos avanços e esforços no sentido de aprimoramento desse nível de ensino alguns problemas estruturais ainda persistem e dificultam a institucionalização e consolidação da pós-graduação brasileira. Destaque para os problemas que subsistem: a excessiva dependência de recursos orçamentários, a sujeição a repentinos cortes de verbas, a instabilidade empregatícia e profissional dos docentes, técnicos e pessoal de apoio, continuam sendo problemas básicos da pós-graduação atual. Além desses problemas são apontadas outras dificuldades específicas da pósgraduação, como a inexistência de um número satisfatório de professores em condições de responder às necessidades de todos os programas existentes; a abertura de cursos em áreas saturadas, por especialidade ou região; a tendência à proliferação de cursos em especialidades que requerem pequeno volume de investimentos (BRASIL, 1982).

Ao realçar tais problemas reconhece que os mesmos comprometem o desempenho do sistema e a qualidade da pós-graduação. A qualidade se difunde onde são criadas as condições necessárias ao seu surgimento e, principalmente, onde se reivindica. No caso, a qualidade da pós-graduação deveria ser pleiteada por três categorias: o mercado, a própria comunidade científica e as instituições governamentais envolvidas (BRASIL, 1982).

Os objetivos do II Plano devem ser direcionados precipuamente para a solução dos problemas considerados centrais e que condicionam o desempenho e o aperfeiçoamento do sistema de pós-graduação. Todos os esforços devem ser concentrados na consolidação e no desenvolvimento do aumento qualitativo do desempenho do sistema como um todo, criando estímulos e condições favoráveis, bem como acionando mecanismos de acompanhamento e avaliação (BRASIL, 1982).

Em relação à ênfase na qualidade deve se apoiar basicamente no aperfeiçoamento dos sistemas de avaliação da pós-graduação e ter a participação ativa da comunidade científica e de todos os envolvidos no processo. Aponta a 
participação de consultores científicos como importantes componentes no processo de avaliação da pós-graduação brasileira.

O III Plano Nacional de Pós-Graduação aprovado foi o primeiro plano elaborado após o período militar, com validade para o quadriênio 1986-1989 estava em consonância com o Plano Nacional de Desenvolvimento (PND), fixou os objetivos, as prioridades e as diretrizes e as estratégias da pós-graduação brasileira. Dividido em seis partes o plano retrata as premissas básicas da política nacional de pós-graduação, a situação da pós-graduação, o papel da pós-graduação no contexto nacional, as diretrizes gerais e as estratégias que devem permear a pós-graduação nacional. Ao apresentar uma breve análise histórica dos dois primeiros planos nacionais de pós-graduação indica os avanços, as conquistas e a evolução do sistema nacional de pós-graduação. Contudo, e apesar de considerar que houve progresso no processo de institucionalização da pós-graduação nas universidades, esse processo continua inacabado, motivo pelo qual esse deverá prosseguir, acrescido de um esforço para a institucionalização e ampliação das atividades de pesquisa como elemento indissociável da pós-graduação (BRASIL, 1986).

O III PNPG se mantém as questões e diretrizes do II PNPG ocorrendo uma expansão moderada dos SNPG impulsionada principalmente pela crescente procura por qualificação profissional oriunda dos setores produtivos e da abertura de novos cursos em regiões até então pouco desenvolvidas, como as regiões Norte, Nordeste e Centro-Oeste (MEGID NETO, 1999).

O III PNPG enfatiza três principais objetivos gerais, a consolidação e melhoria do desempenho dos cursos de pós-graduação; a institucionalização da pesquisa nas universidades para assegurar o funcionamento da pós-graduação e a integração da pós-graduação no sistema de Ciência e Tecnologia, inclusive com o setor produtivo (BRASIL, 1986).

As premissas que orientam o III PNPG são classificadas em: considerar que a pós-graduação é parte integrante do Sistema Educacional e do Sistema de Ciência e Tecnologia, e depende do funcionamento adequado destes para a sua evolução; cabe à pós-graduação o duplo papel de formar recursos humanos de alto nível e de contribuir, por meio da pesquisa, para a solução de problemas sociais, econômicos e 
tecnológicos; a universidade é o local privilegiado para a formação e o aperfeiçoamento cultural, científico e profissional do pessoal de alta qualificação, por meio da pós-graduação; a consolidação da pesquisa e da pós-graduação e a expansão da base científica nacional são objetivos do governo e da sociedade; a expansão da base científica nacional se faz necessária para atender às políticas e estratégias de desenvolvimento científico e tecnológico e às necessidades do sistema educacional e do mercado de trabalho; a existência e disponibilidade de recursos suficientes para implementação dos objetivos do Plano (BRASIL, 1986).

O III PNPG direciona as ações e estratégias da pós-graduação nacional para sete orientações específicas: 1) estimular e apoiar as atividades de investigação científica e tecnológica que devem transcender o processo de capacitação de pessoal de alto nível e se constituir em condição necessária para a realização da pósgraduação; 2) consolidar as instituições universitárias enquanto ambientes privilegiados de ensino e de geração de conhecimentos e promover a institucionalização da pesquisa e da pós-graduação por meio de verbas orçamentárias específicas; 3) consolidar a pós-graduação, ao garantir sua qualidade e assegurar o seu papel como instrumento de desenvolvimento científico, tecnológico, social, econômico e cultural; 4) assegurar os recursos para manutenção da infraestrutura do sistema e manter o financiamento a projetos específico de ensino e pesquisa, através das agências de fomento; 5) garantir a participação da comunidade científica, em todos os níveis, processos e instituições envolvidas na definição de políticas, na coordenação, no planejamento e na execução das atividades de pósgraduação; 6) ensejar e estimular a diversidade de concepções e organizações evitando práticas uniformizadoras entre regiões, instituições e áreas do conhecimento; 7) assegurar condições ao estudante-bolsista para dedicação integral à pós-graduação (BRASIL, 1986). É primeira vez que se considera a necessidade e importância da participação da comunidade científica no processo com um todo, desde a elaboração das políticas até a execução das atividades de pós-graduação.

O IV Plano Nacional de Pós-Graduação aprovado em dezembro de 2004, com validade para o quadriênio 2005-2010, fixou os objetivos, as prioridades e as diretrizes e as estratégias da pós-graduação brasileira para o referido período. Dividido em cinco partes o plano faz um panorama geral da pós-graduação e da 
repercussão dos planos anteriores e propõe encaminhamentos para o desenvolvimento e expansão da pós-graduação brasileira.

O IV PNPG compreende que o sistema educacional é fator estratégico no processo de desenvolvimento nacional e constitui uma referência institucional imprescindível à formação de recursos humanos altamente qualificados e ao fortalecimento da promoção científica e tecnológica nacional. É no cerne do Sistema Nacional de Pós-Graduação que fundamentalmente ocorre a atividade de pesquisa científica e tecnológica e que cabe à pós-graduação a função de formar profissional capacitados a atuarem nos diversos setores da economia e contribuir para o processo de modernização nacional (BRASIL, 2004).

Para os membros da Comissão IV PNPG e considerando os resultados auferido é possível afirmar que a pós-graduação brasileira se constitui numa das realizações bem-sucedidas do sistema de ensino nacional. Julgam que o desenvolvimento da pós-graduação não resultou de um processo espontâneo do aumento da pesquisa científica e da formação de pesquisadores, mas foi decorrência de uma política deliberada conduzida e apoiada por políticas públicas, por instituições públicas e, fundamentalmente, pelo comprometimento da comunidade acadêmica e científica brasileira (BRASIL, 2004).

O Plano evidencia os principais problemas enfrentados pela pós-graduação brasileira em sua trajetória histórica: a falta de planejamento para orientar o crescimento organizado do Sistema; as assimetrias e desigualdades regionais e estaduais, bem como as assimetrias das áreas de conhecimento; o descompasso entre o índice de crescimento de matrículas e titulações e a disponibilidade do número das bolsas; o número insuficiente de programas de pós-graduação nas regiões Norte, Nordeste e Centro-Oeste e a falta de maior articulação entre as agências federais de fomento (BRASIL, 2004).

O objetivo geral do IV PNPG é o crescimento equânime do sistema nacional de pós-graduação, com o propósito de atender, com qualidade, as diversas demandas da sociedade, visando ao desenvolvimento científico, tecnológico, econômico e social do país (BRASIL, 2004). 
Como propostas de diretrizes gerais do plano. Propõe-se o crescimento do sistema como um todo e sugerem-se modelos alternativos e ações que atendam às necessidades regionais, considerando o planejamento estratégico do país. São discutidos novos modelos e políticas de cooperação internacional, visando ao aprimoramento do sistema. Reafirma-se que a avaliação deve ser baseada na qualidade e excelência dos resultados, na especificidade das áreas de conhecimento e no impacto desses resultados na comunidade acadêmica e empresarial e na sociedade (BRASIL, 2004).

O presidente da CAPES Jorge Almeida Guimarães Neves publicou em 05 de fevereiro de 2010 a portaria $n^{\circ}$ 36/CAPES que instituiu a Comissão Nacional responsável pela elaboração do Plano Nacional de Pós-Graduação (2011-2020). A comissão era composta por 17 membros entre docentes e pesquisadores de Universidades Federais e das três Universidades estaduais de São Paulo, representante do Ministérios da Ciência e Tecnologia, representante do CNPq, representante do Ministério da Defesa e representante da Associação Nacional de Pós-Graduandos (ANPG). A Comissão contou com a colaboração de uma comissão coordenadora e de uma comissão de apoio técnico, o prazo para entrega do PNPG (2011-2020) foi 30 de outubro de 2010.

O PNPG define como seu principal objetivo definir novas diretrizes, estratégias e metas para dar continuidade e avançar nas propostas para a política de pós-graduação e pesquisa no Brasil. O documento informa que está sendo elaborado o novo Plano Nacional de Educação (PNE) e que pela primeira vez, um plano nacional de educação contemplará as propostas de diretrizes e políticas do ensino de pós-graduação, isso porque o PNPG será parte integrante do PNE (BRASIL, 2010). É importante ressaltar que o PNE trata da pós-graduação especialmente nas matas 14 (quatorze) e 16 (dezesseis).

\section{PNPG (2011-2020): objetivos e metas}

O V Plano Nacional de Pós-Graduação publicado em dezembro de 2010 com validade para o quadriênio 2011-2020, contêm 2 (dois) volumes. O primeiro volume com 309 páginas e o segundo volume denominado de documentos setoriais 
com 608 páginas. O primeiro volume esta segmentado em 13 itens e organizado em cinco eixos norteadores: 1) a expansão do Sistema Nacional de Pós-Graduação (SNPG), a primazia da qualidade, a quebra da endogenia e a atenção à redução das assimetrias; 2) a criação de uma nova agenda nacional de pesquisa e sua redução das assimetrias; 3) o aperfeiçoamento da avaliação e sua expansão aperfeiçoamento da avaliação e sua expansão para outros segmentos do sistema de CT\&I; 4) a multi e a interdisciplinaridade entre as principais características da pós-graduação; 5) o apoio à educação básica e a outros níveis e modalidades de ensino, especialmente o ensino médio.

Neste contexto, o quinto plano é gestado levando em conta o otimismo que o país está atravessando. O próprio PNPG (2010, p,17), destaca que "trata-se de um fato extraordinário, revelando que o país vem passando e deverá passar mais ainda por mudanças e impactos em diferentes setores da sociedade, inclusive no sistema educacional, e aí incluindo o ensino superior". De acordo com Trevisol, Fávero e Almeida (2020), o entusiasmo é comprovado pelo desenvolvimento do agronegócio, pela descoberta do pré-sal e pela transformação dos índices demográficos o que implica a chegada de jovens ao ensino superior.

A organização do plano (2011-2020) foi pensado e redigido para aproveitar as oportunidades em cenário nacional e internacional. A pós-graduação em seus aspectos como de internacionalização, pesquisa e avaliação devem estar alinhadas com essa perspectiva e garantir a sinergia, em vista de favorecer a integração do ensino de pós-graduação com o setor empresarial e a sociedade.

A primeira prioridade, apontado no PNPG (2011-2020), é o combate as assimetrias. De acordo com o quinto plano, a novidade será o foco nas mesorregiões, cuja formatação dará aos órgãos de governo uma ferramenta mais precisa que o foco em unidades ou em macrorregiões. A perspectiva do combate das assimetrias, coloca a pós-graduação como uma condição de formação qualificada de profissionais para atuar nas regiões, sobretudo, no interior do Brasil. A ênfase dada no Plano é a formação de recursos humanos para empresas e para os programas de desenvolvimento nacional como por exemplo na área de saúde e emergia. 
A segunda prioridade, está relacionado a criação da agenda nacional de pesquisa. Esta agenda de pesquisa deve ser organizada, (PNPG 2010, p. 18), “em torno de temas, de acordo com a relevância de pesquisa para o cenário nacional e internacional". Neste caso, os esforços da pós-graduação é produzir conhecimento para atender as demandas potencialmente mais necessárias para colocar o país em lugar de destaque mundial.

A terceira prioridade é a consolidação de programas de mestrado e doutorado inter e multidisciplinares. O texto do PNPG (2010, p. 18) coloca essa questão ao apontar que "além dos campos disciplinares e seus objetos recomendados, haverá os temas e problemas, dando vazão a cursos inter e multidisciplinares". A interdisciplinaridade e os diálogos entre áreas na elaboração de programas de pós-graduação são apontados pelo documento como uma das metas a ser perseguida no decênio 2011-2020.

As três prioridades estão interligadas com a pesquisa que é o núcleo central do documento. Os resultados da pesquisa na pós-graduação, ao serem aplicados devem levar ao desenvolvimento de tecnologias e procedimentos que podem ser utilizados em setores privados e públicos. A tecnologia é reconhecida no plano como poderosa ferramenta do desenvolvimento econômico e social do país. Por isso, a pesquisa no PNPG (2011-2020), é organizado a partir da tríplice hélice. Esse modelo (PNPG, 2010, p. 18), coloca no centro do plano a "Agenda Nacional de Pesquisa, com a participação de todas as agências de fomento federais e estaduais, com repercussão no SNPG e como matéria de políticas públicas, conduzindo a ações induzidas e parcerias entre universidades e os setores público e privado”. A ênfase é a entrada da esfera privada na pesquisa.

A condição do plano alinhado com a lógica global da "economia do conhecimento" levou a crítica de profissionais da área. Para Barreto e Domingues (2012, p. 50), por exemplo, “o modelo da tríplice hélice, ao instalar a parceria universidade/governo/empresa ou outras instituições" favorece a organização de uma agenda de pesquisa na pós-graduação que pode priorizar áreas estratégicas para o campo privado. No mesmo sentido, Azevedo, Oliveira e Catani (2016), apontam que a proposta de uma agenda nacional de pesquisa, baseada nos preceitos da 
concorrência, inovação e tecnologias materiais desencadeia um processo de desapreço à pesquisa na área das humanidades.

O atendimento a essa condição expressa no PNPG (2011-2020) induz a elaboração de instrumentos regulatórios de avaliação e de financiamento dos programas de pós-graduação baseados na produtividade quantitativa. Neste sentido, Almeida, Fávero e Trevisol (2019), consideram que os critérios quantitativos de avaliação, sobretudo de publicações, papers, dissertações, teses e livros passaram a ser objetivos perseguidos pelos programas, visto que, o número de publicações (Qualis) é um dos critérios centrais para o recebimento de aportes financeiros para os programas. A corrida por publicações nem sempre é acompanhada de qualidade e relevância social para as regiões de atuação dos programas de pós-graduação. O próprio Bianchetti (2006, p.177) já alerta para essa questão ao afirmar que a lógica da CAPES "pode ser sistematizada predominantemente numa palavra mágica: 'prazos'. O todo sucumbe às partes". Para pesquisadores do campo educacional como Ivashita e Vieira (2017), consideram esse tipo de avaliação punitiva, pois, somente seriam aprovados de financiamento vultosos aqueles programas que possuem uma pontuação invejável. A dualidade entre quantidade versus quantidade das publicações se apresenta como um gargalo e uma fragilidade no PNPG (20112020).

No caminho de consolidação do PNPG (2011-2020), demandas e limitações foram apontadas nos relatórios de acompanhamento reborados pela CAPES. Em especial, destacamos os relatórios de 2016, 2018 e 2019 que apontam as metas e conquistas atingidas e as fragilidades e limitações propostas.

O relatório CAPES (2016), apresenta recomendações que devem ser observadas para os próximos anos. Um dos movimentos percebíveis é relacionado aos critérios de avaliação. Neste sentido, a avaliação dos programas de pósgraduação devem atender além das questões acadêmicas as pressões e demandas sociais e empresariais, isto é, os programas serão avaliados pela sua inserção nas demandas sociais e pelas suas relações com o capo produtivo/empresarial. As recomendações do relatório (2016) podem ser condensadas em duas esferas. A primeira é instituir uma avaliação diferenciada para os programas 6 e 7. A segunda é 
instituir padrões internacionais de avaliação nos programas com o objetivo de buscar a excelência na pesquisa similar aos internacionais.

O relatório CAPES (2018), por meio de uma sistemática análise das metas e conquista do PNPG (2011-2020) pontua diversas sugestões e encaminhamentos para os próximos anos, dentre eles merecem destaque, a saber; redefinição do Qualis, solicitar aos programas de pós-graduação apresentem junto a ficha de avaliação quatro produtos (artigos, teses, patentes, etc) e cinco dissertações e teses que representem as produções acadêmicas mais qualificada e solicitar que os professores pertencentes ao corpo docente permanente do programa apresentem três produtos mais significativos (maior impactos) no quatriênio. Estes são alguns dos apontamentos do relatório de 2018 que serão observados para os anos restantes do PNPG (2011-2020).

O relatório de 2020 da CAPES intitulado ' Proposta de Aprimoramento da Avaliação da Pós-Graduação Brasileira para o quadriênio 2021-2024 - Modelo Multidimensional', mantem a mesma linha organizacional para os Programas de Pós-Graduação já expressos nos PNPG (2011-2020) e nos relatórios anteriores. No entanto, a comissão de acompanhamento do PNPG (2011-2020) sugere mudanças relativas ao processo de avaliação que devem ser implementadas no quadriênio 2021-2024.

O relatório CAPES 2020, considera positivamente os avanços da pósgraduação no Brasil, destacando a visibilidade nacional e internacional. O SNPG apresentou nos últimos anos a ampliação de sua rede de mestrados e doutorados. De acordo com o relatório (2020), o SNPG conta com 3.663 mestrados e 2.045 doutorados acadêmicos e 852 mestrados e 37 doutorados profissionais distribuídos por todas as áreas de conhecimento, além, da produção de pesquisas de impacto internacionais. Embora esses dados sejam animadores, o Relatório (2020), apresenta preocupação com gargalos da pesquisa brasileira, dentre elas, o número insuficiente de doutores e cientista para cada cem mil habitantes se comparado, por exemplo com os países da OCDE, a dificuldade de transferência de conhecimento para a sociedade e a dificuldade de ampliação da produção de pesquisa de impacto internacional. 
Para melhorar a pós-graduação, o SNPG considera fundamental o aperfeiçoamento conceituais e operacionais da avaliação. As principais demandas salientadas no Relatório de 2020 que merecessem destaque na avaliação são: a internacionalização, interação com os setores externos da acadêmica, maior protagonismo no processo de desenvolvimento socioeconômico e a redução das assimetrias regionais.

Neste percurso, o relatório CAPES (2020) é organizado a partir do Novo Marco Legal da Ciência, Tecnologia e Inovação que pretende redimensionar a ciência e a tecnologia para o desenvolvimento tecnológico com vista a aumentar a competividade brasileira em cenário internacional. Segundo o relatório, o Novo Marco legal da Ciência Tecnologia e Inovação contribuirá para superar algumas demandas próprias dos programas de pós-graduação, em especial, a aproximação do setor empresarial com a pesquisa acadêmica e a abertura da universidade para demandas externas.

Para a efetividade dos objetivos propostos o Relatório 2019 propõe a organização da avaliação da Pós-graduação a partir do Modelo Multidimensional já apresentado pela comissão de 2018. De acordo com os dois Relatórios 2018-2020, o sistema de avaliação baseado em um formato único, rígido e com padrão definido para todos os programas inviabiliza dados mais qualificados. O modelo de avaliação único deixa de considerar as particularidades dos programas e o contexto que estão inseridos. Assim, o Relatório (2020, p. 09), apesenta um modelo multidimensional com 5 dimensões. Ao final do ciclo avaliativo, "cada PPG terá um resultado para cada dimensão da avaliação, permitindo assim avaliar os respectivos e diferentes desempenhos de cada uma delas e, deste modo, reconhecer a qualidade dos PPGs nas 5 dimensões avaliadas". As cinco dimensões que compões o sistema de avaliação são: formação pessoal, pesquisa, inovação e transferência de conhecimento, impacto na sociedade e internacionalização ${ }^{1}$.

1 Registramos que devido ao comprometimento com o número de caracteres sugeridos pela revista não é será possível trabalhar as cinco dimensões avaliativas apresentadas. Contudo, sugerimos a leitura do Relatório 'Proposta de Aprimoramento da Avaliação da Pós-Graduação Brasileira para o Quadriênio 2012-2014 - modelo Multidimensional", 
Em síntese, o relatório (2020, p. 28), considera a necessidade de dar atenção especial às propostas que envolvem mudanças expressivas com relação ao modelo atual, "especialmente a adoção do modelo multidimensional, a extinção do Qualis, a adoção de participação de membros externos na comissão de avaliação da dimensão Impacto na Sociedade e a exigência do planejamento institucional da pós-graduação por parte das ICTs". A recomendação da comissão especial de acompanhamento de PNPG 2011-2020, é que avaliação da produção, em cada área de conhecimento, abandone o Qualis e adote o sistema de métricas internacionais que são aceitas e reconhecidas pela comunidade acadêmica.

A comissão reconhece os impactos das recomendações e, por isso, orienta que sejam implementadas nos PPGs gradativamente a partir de 2021 estendendo-se até 2024. O relatório 2020 sobre o PNPG (2020-2021), a partir de suas considerações, propostas, metas e objetivos nos dão indicativos sobre os caminhos da pós-graduação no Brasil. Notoriamente, os preceitos e orientações do Relatório 2020 estão de acordo com o contexto histórico e asseguram a lógica produtiva do capital de acumulação flexível que trata o conhecimento como mais um recurso para a economia. Portanto, o PNPG (2011-2020), bem como os seus relatórios subsequentes adotam as designações mundiais, materializa nos relatórios da UNESCO OCDE e Bando Mundial.

A crise pela qual passam os sistemas educacionais pode ser explicada também sob essa ótica, considerando que a qualidade e eficácia da educação deixam de ser o fim último do processo de ensino, colocando à frente dos programas e reformas destinados à melhoria da educação a lógica de mercado segundo a qual a educação também se torna um bem comercializável e nela se formam também seres comercializáveis que venderão sua força produtiva para manterem a própria subsistência.

Para Gentili (1996, p. 4), "em primeiro lugar é necessário destacar que na perspectiva neoliberal os sistemas educacionais enfrentam, hoje, uma profunda crise de eficiência, eficácia e produtividade", mais do que uma crise de quantidade,

especialmente, entre as páginas 09 e 22 para entendimento das metas, objetivos e propostas de avaliação dos PPGs considerando as cinco dimensões. 
universalização e extensão. Isso nos leva a pensar que essa realidade se traduz na proliferação de cursos, de faculdades, de possibilidades de formação de professores e pesquisadores, a maioria voltada para a formação tecnicista que privilegia a inserção de profissionais no mercado de trabalho e afasta o ideal de liberdade e igualdade de direitos a todos os cidadãos, uma vez que a educação se torna produto de troca de um sistema capitalista.

Contudo, não podemos deixar de pensar que nenhuma ação voltada para o sistema educacional se desenvolve sem que haja a participação do Estado com políticas públicas condizentes às necessidades de uma educação humanizadora. Nesse sentido, entendemos com Mészáros (2010) que é preciso uma "educação para além do capital", o que enseja uma "ordem social qualitativa diferente":

Pois as incorrigíveis determinações destrutivas da ordem existente tornam imperativo contrapor aos irreconciliáveis antagonismos estruturais do sistema do capital uma alternativa concreta e sustentável para a regulação da reprodução metabólica social, se quisermos garantir as condições elementares da sobrevivência humana. O papel da educação, orientado pela única perspectiva efetivamente viável de ir para além do capital, é absolutamente crucial para esse propósito (MÉSZÁROS, 2010, p. 72).

Para que se desenvolva uma educação diferente da praticada nas escolas brasileiras, que privilegia as desigualdades, que semeia e reproduz uma ideologia que mercantiliza tudo, até mesmo os processos educacionais, Mészáros entende que se deve manter, sob a ótica de ir além do capital, um processo de formação constante, porque isso requer tempo e que seus atores estejam atualizados porque a sociedade, as ideologias e o conhecimento estão em constante transformação.

\section{Considerações finais}

Frente ao ideário liberal recente, o caráter público da universidade e da pesquisa científica é susceptível de várias interpretações por parte dos próprios acadêmicos. A educação apresenta-se como uma forma de preparar o indivíduo para trabalhar em equipe e saber lidar com o imprevisto. O problema da pesquisa, 
enquanto trabalho acadêmico, é compreendido em função da relação da Universidade com o mercado - as demandas empresariais.

De um modo geral, a visão liberal, em todas as suas fases, tem sido caracterizada pela preocupação com as possibilidades de manutenção e atualização da produção. O papel da pesquisa é estratégico nesse processo.

[...] O argumento a respeito dos benefícios sociais da pesquisa não considera o fato de que a ciência se tornou, em si mesma, um importante empreendimento econômico. Hoje, os cientistas constituem um grupo de interesse que compete por recursos com outros grupos de interesse, e por isso pode participar de conflito de classe (DAVID, 1971, p. 249).

A institucionalização do SNPG na década de 1960 é reconhecidamente um passo decisivo em favor do desenvolvimento da pós-graduação no Brasil e para a consolidação de uma agenda de pesquisa sistemática e com objetividade aos interesses desenvolvimentistas no país. O resultado da institucionalização do SNPG resultou em 1980 com a consolidação da pós-graduação. As universidades passaram a organizar os cursos de mestrado e doutorado com objetivo de formar e qualificar professores e pesquisadores para atuar no ensino superior.

Com a necessidade de organizar a pesquisa e a pós-graduação no Brasil, o SNPG passou a elaborar os planos nacionais de pesquisa que possuem como prioridade desenhar e orientar a pesquisa, os objetivos e as finalidades da produção de conhecimento para o país. No decorrer dos cinco planos um discurso comum perpassa toda a historicidade desses documentos. Merece destaque, a forte preocupação de que a pós-graduação seja voltada para o desenvolvimento de áreas estratégicas para o desenvolvimento do país no cenário internacional, sobretudo, voltadas para as tecnologias e a inovação. Um segundo elemento, presente os planos é a necessidade latente de formar mestres e doutores para a atuação no ensino superior e no desenvolvimento de pesquisas. O terceiro elemento que merece destaque é a formalização de critérios avaliativos, linhas de pesquisa e financiamento dos programas de pós-graduação.

Considerando o contexto histórico de cada um dos cinco planos nacionais de pós-graduação é possível perceber a introdução de novas preocupação. O IV PNPG introduziu em sua formulação a preocupação com as assimetrias regionais, as 
desigualdades entre os programas de pós-graduação, a internacionalização e como objetivo, a necessidade de que o Brasil melhore sua posição de publicações no Ranking mundial. No campo da avaliação, o IV PNPG define o critério do Qualis como um elemento importante para o credenciamento e avaliação dos PPGs.

Neste sentido vale a pena relembrar o que disse Ben David há quase cinquenta anos atrás: "[...] O argumento a respeito dos benefícios sociais da pesquisa não considera o fato de que a ciência se tornou, em si mesma, um importante empreendimento econômico. Hoje, os cientistas constituem um grupo de interesse que compete por recursos com outros grupos de interesse, e por isso pode participar de conflito de classe” (DAVID, 1971, p. 249)

O V PNPG reconhece os avanços da pós-graduação no Brasil, mas considera importante o investimento e financiamento para a pesquisa em áreas estratégicas vinculadas a ciência e tecnologia, que são consideradas decisivas para colocar o país nos mesmos patamares internacionais de crescimento. Por isso, mantém o mesmo discurso do IV PNPG, suas metas e objetivos, no entanto, introduz a internacionalização como um elemento central, acentua a importância da publicação quantitativa como critério de avaliação do PPGs, define o Qualis e constitui uma agenda de pesquisa fundada na relação triática entre PPGs, empresas e a sociedade. O objetivo da agenda nacional de pesquisa é abrir os PPGs para demandas extremas e, portanto, desenvolver pesquisas de ordem aplicada.

As metas e objetivos do PNPG (2011-2020) são avaliados pelos relatórios produzidos pela CAPES. Dentre eles, o relatório (2019) ganha destaque pelo fato que propor mudanças substanciais, dentre elas, a consolidação da avaliação dos PPGs a partir do modelo multidimensional, o abandono do Qualis e a introdução do sistema de métricas internacionais, além de considerar como um critério decisivo a observação da inserção e missão de cada PPGs possui com sua região de atuação.

Portanto, é notório a importância do SNPG e dos Planos Nacionais de PósGraduação para o desenvolvimento do país e da pesquisa. No entanto, deve-se considerar que os PNPGs mantêm uma organização em torno de ideais economicistas, de caráter competitivo e alinhado a agenda mundial de pesquisa que valoriza áreas consideradas estratégicas para o crescimento do PIB dos países. Deste 
modo, as áreas das humanidades são frequentemente desvalorizadas, sendo obrigadas a se adequar a sistemas de avaliação e financiamento que não são comuns aos seus procedimentos investigativos. No interior dessa discussão, os apontamentos permitem questionar o lugar das humanidades no PNGP (2011-2020) e sobre qual o futuro da pesquisa nas humanidades para a próxima década que se avizinha.

Vale a pena ressaltar ainda que, o liberalismo, de um modo ou de outro, sempre necessita de um poder central de agregação capaz de manter a ferro e fogo certas tendências conforme os interesses do capital. E a produção da pesquisa não é uma exceção. Uma democracia radical, isto é, em que as bases determinariam os rumos a serem dados à pesquisa pública, seria totalmente imprevisível, podendo caminhar tanto no sentido de estabelecer a tirania, portanto de negar a si mesma, como também de evoluir num sentido comunista, ambos contrários ao consenso liberal. Nesse sentido, o Estado Liberal será sempre um poder em prontidão, ainda que recue ao máximo possível. Caberá a ele manter o consenso ou a hegemonia burguesa, não importando por qual meio. Como vimos, para alcançar tal objetivo, vale lançar mão até do planejamento -Keynes- quando este for conveniente. O ideal burguês da liberdade de empreendimento e harmonia entre interesses egoístas particulares e a investigação cientifica pública, além de supor a desigualdade como natural, e constituindo o mesmo motor da economia, admite um Estado de prontidão ou guarda noturno, capaz de manter as tendências determinadas pelo mercado. A sociedade liberal precisou sempre de um poder coercitivo, ainda que não ostensivo diante desta realidade polêmica que se apresenta os Planos Nacionais de Pós-graduação na história da educação brasileira.

À universidade, cabe sempre as palavras de Marx (s/d, p. 208):

os homens são produto das circunstâncias e da educação e, portanto, homens modificados são produto de circunstâncias diferentes e de educação modificada; esquece-se que as circunstâncias são modificadas precisamente pelos homens e que o próprio educador precisa ser educado.

A práxis, enquanto ação ética e política de persuasão e influência que homens exercem sobre si, estão enraizada na atividade acadêmica, de modo que os acadêmicos se circunscrevem na superestrutura, no campo da luta política. Dentro 
dessa perspectiva, o pensamento de Gramsci é fundamental para compreender o papel do intelectual. Inicialmente, destaque-se que ele amplia a concepção de Estado do marxismo "clássico", mostrando que a luta política nas sociedades atuais se dá menos contra o Estado que no Estado, o qual se apresenta como instância mediadora de interesses de classes, em vez de mero representante da classe dominante.

Ao caracterizar o político como esfera do constrangimento, em que a força é usada para manter tendências, e o privado, enquanto campo da luta ideológica, Gramsci (1991) indica uma nova forma de se pensar o público, no nosso caso, isso vale para pesquisa pública. Trata-se do coletivo enquanto organicidade, em que os vínculos se estreitam e se soldam, de modo a integrar as manifestações singulares, de incorporá-las num bloco. A hegemonia significa que o público assim constituído se apresenta como universal ou comum, ainda que não o seja. Gramsci (1991) fala de várias formas de se obter a vontade coletiva. Uma delas "é a constituída de indivíduos singulares, os quais formam o organismo na medida em que se entregam e aceitam ativamente uma hierarquia e uma direção determinadas". (GRAMSCI, 1991, p.177). Essa consciência coletiva se forma conforme um consenso ativo e direto, com a participação dos indivíduos, com o atrito entre eles, "mesmo que isso provoque uma aparência de desorganização e tumulto". Neste caso o organismo não é estranho aos indivíduos. Parafraseando Marx: Pesquisadores do Mundo, uni-vos!

\section{Referências}

ALMEIDA, M. L. P.; FÁVERO, A. A.; TREVISOL, M. G. Pesquisa e avaliação no PNPG (2011-2020): fragilidades e potencialidades. Rev. Eletrônica Pesquiseduca. Santos, v. 11, n. 25, p. 303-324, set./dez. 2019.

ALVES, M. F.; OLIVEIRA, J. F. Pós-Graduação no Brasil: do Regime Militar aos dias atuais. Revista Brasileira de Política e Administração da Educação, [S.I.], v. 30, n. 2, fev. 2015.

AZEVEDO, M. L. N.; OLIVEIRA, J. F.; CATANI, A. M. o sistema Nacional de Pósgraduação (SNPG) e o Plano Nacional de Educação (PNE 2014-2024): regulação, avaliação e financiamento. RBPAE, v.32, n,3, p. 783-808, set./dez.2016.

BARRETO, F. C. S.; DOMINGUES, I. Os desafios do país e o sistema nacional de pósgraduação. Educação em revista, Belo Horizonte, v. 28, n. 03, p. 17-53, 2012. 
BARROS, E. M. C. Política de pós-graduação no Brasil (1975-1990): um estudo da participação da comunidade científica. São Carlos: Editora da UFSCar, 1998.

BIANCHETTI, L. Os dilemas do coordenador do Programa de Pós-Graduação: entre o burocrático-administrativo e o acadêmico-pedagógico. In: BIANCHETTI, L.; SGUISSARDI, V. (org). Dilemas da Pós-Graduação: gestão e avaliação. Campinas/SP: Autores Associados, 2009.

BIANCHETTI, L. O desafio de escrever dissertação/tese: como incrementar a quantidade manter a qualidade com menos tempo e menos recursos? In: BIANCHETTI, L.; MACHADO, A. M. (Org). A buissola do escrever. desafios e estratégias na orientação e escrita de teses e dissertações. 2. ed. Florianópolis: ed. Da UFSC: São Paulo: Cortez, 2006.

BRAIL. Diretrizes e Bases da Educação Nacional Lei n. 4.024. Brasília, DF, 1961. Disponível em: https://www2.camara.leg.br/legin/fed/lei/1960-1969/lei-4024-20-dezembro-1961353722-publicacaooriginal-1-pl.html. Acesso em: 10 set. 2020.

BRASIL. I PNPG - Plano Nacional de Pós-Graduação. Brasília, DF, 1975. Disponível em: https://www.capes.gov.br/images/stories/download/editais/I_PNPG.pdf. Acesso em: 15 set. 2020 .

BRASIL. II PNPG - Plano Nacional de Pós-Graduação (1982-1985). Brasília, DF, 1982. Disponível em: https://www.capes.gov.br/images/stories/download/editais/I_PNPG.pdf. Acesso em: 15 set. 2020 .

BRASIL. III PNPG - Plano Nacional de Pós-Graduação (1986-1989). Brasília, DF, 1986. Disponível em: http://uab.capes.gov.br/images/stories/download/editais/III_PNPG.pdf. Acesso em: 15 set. 2020.

BRASIL. Plano Nacional de Pós-Graduação - PNPG 2005-2010: coordenação de aperfeiçoamento de pessoal de nível superior. Brasília, DF: CAPES, 2004.

BRASIL. Plano Nacional de Pós-Graduação - PNPG 2011-2020: coordenação de aperfeiçoamento de pessoal de nível superior. v.1.Brasília, DF: CAPES, 2010.

BRASIL. Plano Nacional de Pós-Graduação - PNPG 2011-2020: coordenação de aperfeiçoamento de pessoal de nível superior. v.2.Brasília, DF: CAPES, 2010.

BRASIL. Relatório final 2016: comissão de acompanhamento do PNPG (2011-2020). Brasília: CAPES, 2017.

BRASIL. Proposta de aprimoramento do modelo de avaliaşão da PG: Documento final da comissão de acompanhamento do PNPG 2011-2002. Brasília: CAPES, 2018.

BRASIL. Proposta de Aprimoramento da Pós-Graduação Brasileira para o Quadriênio 2021-2024 - Modelo Multidimensional. Brasília: CAPES, 2020.

COURY, M. A. Ações do Plano Nacional de Pós-graduação (PNPG) 2005-2010 para a redução de assimetrias regionais: avaliação dos instrumentos criados pela CAPES, 2014. 50 f. (Dissertação de Mestrado) - Universidade Federal do Rio Grande/Furg, Programa do Pós-Graduação em Educação e Ciência: química da Vida Saúde, Rio Grande do Sul, 2014. 
DAVID, J. B. O papel do cientista na sociedade. SP. Editora Pioneira, 1971.

IVASHITA, S.; VIEIRA, A. D. R. A pós-graduação no Brasil e o Plano Nacional de PósGraduação - PNPG (2011-2020): rupturas e permanências. Debates em Educação, v. 9, n. 19, p. 122-132, set./dez. 2017.

GENTILI, P. Neoliberalismo e educação: manual do usuário. Escola SA: quem ganha e quem perde no mercado educacional do neoliberalismo. Brasília: CNTE, 1996.

GRAMSCI, A. Maquiavel, a Política e o Estado Moderno. R.J. Ed. Civilização Brasileira, 1991, 8a edição.

MARX, K. Teses de Fauerbach, (II). In: MARX, K.; ENGEL, F. Obras Escolbidas. São Paulo, Alfa-omega, s/d, volume III.

MARX, K. Contribuição crítica para a economia politica. Lisboa: Estampa, 1973.

MARTINS, C. B. As origens pós-graduação nacional (1960-1980). Revista Brasileira de Sociologia, v. 6, p. 9-26, 2018.

MEGID NETO, J. Tendências da pesquisa acadêmica sobre o ensino de Ciências no nível fundamental. 1999. 365 p. Tese (Doutorado em Educação) — Faculdade de Educação, Universidade Estadual de Campinas, Campinas, 1999.

MÉSZÁROS, I. Educação para além do capital. São Paulo: Boitempo, 2005.

OLIVEIRA, J. F. A pós-graduação e a pesquisa no Brasil: processos de regulação e de reconfiguração da formação e da produção do trabalho acadêmico. Práxis Educativa, Ponta Grossa, v. 10, n. 2, p. 343-363, jul./dez. 2015.

TREVISOL, M. G; FÁVERO, A. A; ALMEIDA, M. L. P. Pesquisa e avaliação no PNPG (2011-2020): fragilidades e potencialidades. Rev. Eletrônica Pesquisaeduca, Santos, v. 11, n. 25, p. 303-324, set./dez. 2019.

RECEBIDO: 09/05/2021

APROVADO: 20/09/2021

RECEIVED: 05/09/2021

APPROVED: 09/20/2021

RECIBIDO: 09/05/2021

APROBADO: 20/09/2021 